\title{
Triptolide exhibits antitumor effects by reversing hypermethylation of WIF-1 in lung cancer cells
}

\author{
XIAOLIANG MAO, JICHUN TONG, YONG WANG, ZHENG ZHU, YAJUN YIN and YEMING WANG \\ Department of Cardiothoracic Surgery, Changzhou No. 2 People's Hospital, \\ The Affiliated Hospital of Nanjing Medical University, Changzhou, Jiangsu 213000, P.R. China
}

Received May 5, 2017; Accepted March 21, 2018

DOI: $10.3892 / \mathrm{mmr} .2018 .9263$

\begin{abstract}
Triptolide (TP) exhibits numerous biological activities, including immunosuppressive, anti-inflammatory and antitumor effects. The aim of the present study was to investigate the role of TP as a potent therapeutic drug for the treatment of lung cancer and to investigate the underlying therapeutic mechanisms. Western blot analyses and reverse transcription-quantitative polymerase chain reaction (PCR) were performed to investigate the expression of genes at transcriptional and translational levels, respectively. Methylation-specific PCR assays were conducted to investigate whether TP affects the Wnt inhibitory factor-1 (WIF-1) methylation status and subsequently affects apoptosis, migration or the invasion of lung cancer cells. The results of the present study revealed that the methylation status of WIF-1 in lung cancer cell lines A549 and H460 was significantly enhanced compared with the human normal bronchial epithelial cell line HBE, whereas treatment with TP was revealed to induce the demethylation of WIF-1. The present study aimed to investigate whether the biological activities of TP are regulated by inhibiting the Wnt signaling pathway via an increase in WIF-1 expression levels. The results of the present study revealed that Wnt signaling was suppressed in cells following treatment with TP, which was concluded by the downregulation of Axin 2 and $\beta$-catenin expression. Further investigation demonstrated that the silencing of WIF-1 expression with small interfering RNA reversed the TP-induced upregulation of WIF-1 expression, upregulated Axin 2 and $\beta$-catenin expression and enhanced the activation of Wnt signaling. Notably, an upregulation of cellular tumor antigen p53 expression, and downregulation of matrix metalloproteinase-9 (MMP-9) and phosphorylated-nuclear factor- $\kappa \mathrm{B}(\mathrm{NF}-\kappa \mathrm{B})$ P65 (p-P65) levels
\end{abstract}

Correspondence to: Dr Jichun Tong, Department of Cardiothoracic Surgery, Changzhou No. 2 People's Hospital, The Affiliated Hospital of Nanjing Medical University, 68 Middle Ge Lake Road, Changzhou, Jiangsu 213000, P.R. China

E-mail: erxz9657@126.com

Key words: triptolide, Wnt inhibitory factor-1, methylation, Wnt, cellular tumor antigen $\mathrm{p} 53$, nuclear factor- $\mathrm{\kappa} \mathrm{B}$ was observed following TP treatment. These results suggest that the Wnt, p53 and NF- $\mathrm{NB}$ signaling pathways mediate the potent antitumor effects of TP. Notably, the silencing of WIF-1 did not completely recover the levels of p53, MMP-9 and p-P65 in cells treated with TP compared with the control cells, thus suggesting that TP exhibits further functions in addition to the targeting of WIF-1.

\section{Introduction}

Triptolide (TP) is a traditional Chinese medicine, apredominant active ingredient in Tripterygium wilfordii and is a diterpenoid compound (1). Numerous studies have suggested that TP can inhibit proliferation of numerous tumor cells, such as breast cancer, gastrointestinal cancer, prostate cancer and nervous system tumors (1-3). TP was discovered in 1972 and the molecular mechanism of its biological activities has been extensively studied (4). TP exhibits an immunomodulatory role, predominantly via inhibition of nuclear factor $-\kappa \mathrm{B}(\mathrm{NF}-\kappa \mathrm{B})$, and subsequent suppression of the production of inflammatory factors and thus the immune response of the body $(5,6)$. In addition, TP can induce apoptosis in numerous tumor cell types, predominantly via inhibition of heat shock transcription factor 1 , activator protein 1 (AP-1), NF- $\mathrm{-B}$ and other transcriptional regulators, thus exhibiting an antitumor effect $(5,7)$. Such results suggest that $\mathrm{NF}-\kappa \mathrm{B}$ may be associated with the underlying therapeutic mechanism of TP. Furthermore, these studies demonstrated that functional cellular tumor antigen p53 (p53) is necessary for the performance of the various biological activities of TP (6).

Lung cancer is the most common type of cancerous tumor globally. Despite the possibility of early diagnosis, chemotherapy, radiotherapy and immunotherapy, the 5-year survival rate of lung cancer remains $<15 \%$ (8). Small molecule inhibitors, predominantly epidermal growth factor receptor-associated drugs, including gefitinib and erlotinib, have been reported to have significant antitumorigenic effects with fewer side effects $(9,10)$. Despite the wide use of these drugs, there are significant drug resistances in patients with epidermal growth factor receptor-negative cancer $(9,11)$. Thus, there is an urgent requirement to identify novel antitumor agents that can act on irregularly functioning signaling pathways. It has been reported that Wnt family proteins can regulate cell development and growth via regulation of downstream proteins (12). The 
most predominant proteins associated with the Wnt signaling pathway, from the extracellular to intracellular environment, include the Wnt protein (predominantly encoding secretory glycoprotein), cell membrane Wnt receptor protein, $\beta$-catenin and the anaphase promoting complex protein (glycogen synthase- $3 \beta$ kinase, Axin and conductin) (13). Wnt signaling pathways are generally expressed during embryonic development, and Wnt signaling is subsequently downregulated or absent in mature organisms (14). However, numerous studies have revealed that abnormal expression of Wnt signaling activates the cell cycle, induces proliferation associated with proto-oncogenes and promotes tumorigenesis $(15,16)$. Studies have also demonstrated that the expression of Wnt ligands are upregulated in lung cancer cell lines and tissues $(17,18)$. Overexpression of Wnt ligands results in the ectopic activation of $\beta$-catenin in the cytoplasm/nucleus of lung cells and the activation of transcription of downstream target genes (predominantly encoding a number of proto-oncogenes and cell cycle regulators) (19). Despite the cause of Wnt ligand overexpression in lung cancer cells remaining unclear, one of the notable associated mechanisms is the absence of the Wnt antagonist protein (20). Wnt inhibitory factor-1 (WIF-1) is present in normal cells via binding to Wnt ligands to prevent over activation of the Wnt pathway (21). Studies have revealed that WIF-1 is suppressed in lung cancer cells, thus weakening its binding to Wnt ligands and inhibiting the sustained activation of the Wnt pathway $(22,23)$. In addition, it has been reported that hypermethylation of the WIF-1 promoter is frequently present in lung cancer specimens, with suppressed or absent expression of WIF-1 (23). Therefore, one of the notable causes of abnormal activation of the Wnt pathway in lung cancer cells may be due to hypermethylation of the WIF-1 promoter region, thus resulting in the suppressed regulation of the Wnt ligand expression (22-24). Reversing the hypermethylation of the WIF-1 promoter in lung cancer cells and restoring the expression level of WIF-1 in lung cancer cells, and thus further inhibiting the activation of the Wnt pathway, are important therapeutic targets for the treatment of lung cancer requiring further investigation.

The aim of the present study was to investigate the effect of TP on the proliferation, invasion, migration and apoptosis of human lung cancer cells, and to determine the underlying molecular mechanism of the therapeutic effects of TP on lung cancer cells. The results of the present study will aim to provide a theoretical basis for further study regarding the anticancer effect of TP.

\section{Materials and methods}

Cell culture and treatment. The lung cancer cell lines A549, H460 and NCI-H446, and human normal bronchial epithelial cell line HBE, all purchased from the American Type Culture Collection (Manassas, VA, USA) were used in the present study. The cells were cultured in RPMI-1640 (Gibco; Thermo Fisher Scientific, Inc., Waltham, MA, USA) containing $10 \%$ fetal bovine serum (FBS, Sigma-Aldrich, Merck KGaA, Darmstadt, Germany), penicillin (100 U/ml) and streptomycin $(100 \mu \mathrm{g} / \mathrm{ml})\left(\right.$ Gibco; Thermo Fisher Scientific, Inc.) at $37^{\circ} \mathrm{C}$ with a humidified atmosphere of $5 \% \mathrm{CO}_{2}$. The cells were cultured to $70-80 \%$ confluence prior to further investigation.
Methylation-specific polymerase chain reaction (PCR). A549, H460, NCI-H446 and HBE cells were harvested to detect WIF-1 methylation PCR. Following this, A549 and H460 cells were collected and incubated with $0.03,0.3$ and $3 \mu \mathrm{M}$ TP for $24 \mathrm{~h}$. The methylation-specific PCR protocol was performed as described previously (25). Briefly, the extracted DNA was treated with sodium bisulfite. This treatment ensured that unmethylated cytosine in the $\mathrm{CpG}$ nucleotides was converted to uracil, whereas the methylated cytosine remained unaffected. The modified reaction was performed using an EZ DNA Methylation-Gold kit (Zymo Research Corp., Irvine, CA, USA). Subsequently, the treated DNA was amplified using methylation-specific and non-methylation-specific primers. The thermocycling conditions for PCR amplification: Pre-denaturations $\left(94^{\circ} \mathrm{C}, 5 \mathrm{~min}\right) ; 35$ cycles of denaturation $\left(94^{\circ} \mathrm{C}, 30 \mathrm{sec}\right)$, annealing $\left(56^{\circ} \mathrm{C}, 30 \mathrm{sec}\right)$ and extension $\left(72^{\circ} \mathrm{C}\right.$, $30 \mathrm{sec})$; post-extension $\left(72^{\circ} \mathrm{C}, 5 \mathrm{~min}\right) .2 \mathrm{X}$ PCR Master Mix (Tiangen Biotech Co., Ltd., Beijing, China) was used in these assays. WIF-1 methylation PCR primers were synthesized by Sangon Biotech (Shanghai) Co., Ltd. (Shanghai, China). The following methylation-specific primers were used: forward, 5'-GGGCGTTTTATTGGGCGTAT-3' and reverse, 5'-AAACCAACAATCAACGAAC-3'. The following non-methylation-specific primers were used: forward, 5'-GGG TGTTTTATTGGGTGTAT-3' and reverse, 5'-AAACCAACA ATCAACAAAAC-3'.

Cell proliferation assay. Cell proliferation was investigated via a Cell Counting kit-8 (CCK-8) assay. A549 and H460 cells $\left(5 \times 10^{4}\right.$ cells/well $)$ were seeded in 96 -well plates and incubated with $0.03,0.3$ and $3 \mu \mathrm{M}$ TP for 6,12 and $24 \mathrm{~h}$ time intervals. Subsequently, $20 \mu \mathrm{l}$ of CCK-8 (Dojindo Molecular Technologies, Inc., Kumamoto, Japan) was added into the cells collected from 6, 12 and $24 \mathrm{~h}$ time intervals. Following incubation for $4 \mathrm{~h}$, the absorptions of cells were determined at $450 \mathrm{~nm}$ using an ELISA reader (ELx800TM; BioTek Instruments, Inc., Winooski, VT, USA).

Transwell cell migration assay. A549 cells were digested with $0.25 \%$ Trypsin-EDTA solution, harvested and washed twice to remove serum. Cells were resuspended in Dulbecco's Modified Eagle Medium (DMEM; Sigma-Aldrich; Merck KGaA) and then adjusted to $2 \times 10^{5} / \mathrm{ml}$. Subsequently, $300 \mu \mathrm{l}$ cell solution was added to upper chambers (BD Biosciences, Franklin Lakes, NJ, USA) and then placed on 24-well plate for $2 \mathrm{~h}$. Lower chambers were filled with $500 \mu 1$ DMEM medium containing $2.5 \%$ FBS and incubated for $24 \mathrm{~h}$. Following incubation, migratory cells were fixed with $4 \%$ formaldehyde for $15 \mathrm{~min}$ at room temperature and then stained with $0.1 \%$ crystal violet dyes for $3 \mathrm{~h}$ at room temperature. A total of 5 fields of view were selected randomly, observed and imaged under a light microscope (magnification, x400; 80i; Nikon Corporation, Tokyo, Japan). Absorbance values at $570 \mathrm{~nm}$ were measured using SpectraMax ${ }^{\circledR}$ M5/M5e (Molecular Devices, LLC, Sunnyvale, CA, USA). The migration rate was expressed as the percentage of the control.

Transwell cell invasion assay. Cell migration analysis was performed using an ECM554 invasion kit 


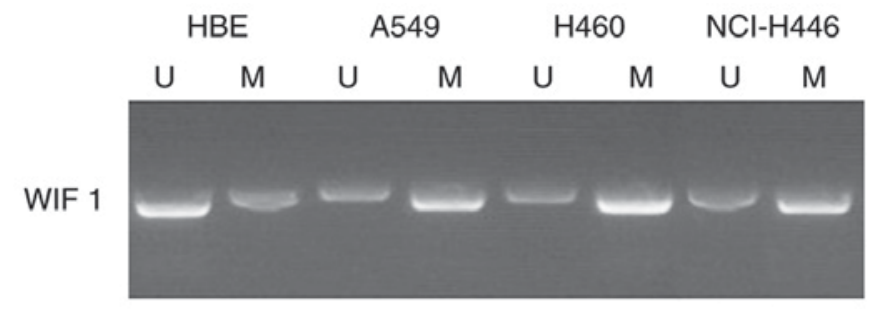

Figure 1. The hypermethylation of WIF-1 promoter in lung cancer cells is enhanced compared with the normal bronchial epithelial cell line HBE cel line. Methylation-specific polymerase chain reaction assay was performed. The results demonstrated that the methylation status in cancer cells was enhanced compared withthe normal bronchial epithelial cell line HBE. U, unmethylated; M, methylated; WIF 1, Wnt inhibitory factor-1.

(Chemicon International; Thermo Fisher Scientific, Inc.) according to the manufacturer's protocol. Briefly, cells from all experimental groups were collected and resuspended in DMEM medium and then adjusted to $2 \times 10^{5} / \mathrm{ml}$. The upper chambers of the Transwell was placed on 24-well plate and $300 \mu \mathrm{l}$ serum free medium was added, and the bottom chambers were filled with DMEM medium containing $2.5 \% \mathrm{FBS}$. Following incubation for $10 \mathrm{~min}, 250 \mu \mathrm{l}$ cell solution was used to replaced the DMEM in the upper chambers and then underwent further incubation for $24 \mathrm{~h}$. Invaded cells were stained using $0.1 \%$ crystal violet dye for $3 \mathrm{~h}$ at room temperature. A total of 5 fields of view were selected randomly, observed and imaged under microscope (magnification, $\mathrm{x} 400$; 80i; Nikon Corporation). The invasion rate was expressed as the percentage of the control.

Cell transfection. At $80 \%$ confluence A549 cells were transfected with WIF1 small interfering (si)RNA sense, 5'-CCUGUCAAU AUCCAUUCCAUU-3' and antisense, 5'-UGGAAUGGAUAU UGACAGGUU-3'; negative siRNA control sense, 5'-UUCUCC GAACGUGUCACGUTT-3' and antisense, 5'-ACGUGACAC GUUCGGAGAATT-3') via Lipofectamine 2000 (Invitrogen; Thermo Fisher Scientific, Inc.) according to the manufacturer's protocols. The medium was replaced with complete DMEM containing 10\% FBS (Sigma-Aldrich; Merck KGaA) following incubation for $5 \mathrm{~h}$ at $37^{\circ} \mathrm{C}$.

Western blot assay. A549 cells were collected and then lysed in radioimmunoprecipitation assay lysis buffer containing $50 \mathrm{mM}$ Tris- $\mathrm{HCl}, 200 \mathrm{mM} \mathrm{NaCl}, 1 \mathrm{mM}$ EDTA, $1 \mathrm{mM}$ EGTA, $1 \%$ Triton X-100, $0.25 \%$ deoxycholate, protease and phosphatase inhibitors. Total protein concentration was determined using the bicinchoninic acid assay (Hyclone; GE Healthcare, Chicago, IL, USA). Total protein (20-40 $\mu \mathrm{g})$ was separated via electrophoresis using 10\% SDS-PAGE gel and the proteins were then transferred electrophoretically onto polyvinylidene fluoride membranes. Following blocking with 5\% non-fat dry milk in TBS containing $0.1 \%$ Tween-20 (TBST) for $1 \mathrm{~h}$ at room temperature, the membranes were incubated with primary antibodies WIF1 (1:1,000; ab224335), p53 (1:1,000; ab26), MMP-9 (1:1,000; ab38898), Axin2 (1:1,000; ab109307), p-P65 (1:1,000; ab176647), P65 (1:1,000; ab16502), $\beta$-catenin $(1: 5,000 ;$ ab32572) and $\beta$-actin $(1: 1,000$; ab8226; all Abcam, Cambridge, MA, USA) overnight at $4^{\circ} \mathrm{C}$. The membranes were then incubated with horseradish peroxidase-conjugated secondary antibody (1:2,000 dilutions; NA934V; GE Healthcare Bio-Sciences, Pittsburgh, PA, USA). Following washing with TBST, the blots were developed using an enhanced chemiluminescence kit (GE Healthcare Bio-Sciences) for $2 \mathrm{~h}$ at room temperature. $\beta$-actin was used as an internal control. Band intensities were quantified by densitometry using ImageJ software (ver 1.45; National Institutes of Health, Bethesda, MD, USA).

Reverse transcription-quantitative PCR assay (RT-qPCR). A549 cells were collected and total RNA was isolated using the RNeasy mini-kit (Qiagen GmbH, Hilden, Germany) according to the manufacturer's protocol. The RNA was then reverse transcribed to cDNA using NCode VILO miRNA cDNA Synthesis kit (Invitrogen; Thermo Fisher Scientific). The temperature conditions for RT were as follows: $30^{\circ} \mathrm{C}$ for $10 \mathrm{~min}, 42^{\circ} \mathrm{C}$ for $30 \mathrm{~min}, 99^{\circ} \mathrm{C}$ for $5 \mathrm{~min}, 4^{\circ} \mathrm{C}$ for $5 \mathrm{~min}$. qPCR was performed using iQ SYBR-Green Supermix on the iCycleriQ thermal cycler (Bio-Rad Laboratories, Inc., Hercules, CA, USA). The thermocycling conditions for qPCR: $50^{\circ} \mathrm{C}$ for $2 \mathrm{~min}, 95^{\circ} \mathrm{C}$ for $10 \mathrm{~min}$, followed by 40 cycles of $95^{\circ} \mathrm{C}$ for $15 \mathrm{sec}$ and $60^{\circ} \mathrm{C}$ for $1 \mathrm{~min}$. All assays were performed in duplicate. Gene expression was quantified using the $2^{-\Delta \Delta C q}$ method (26). Relative mRNA expression was normalized to $\beta$-actin expression. Primers used in this study were as follows: WIF-1 forward, 5'-ATGAATTCCTGTCCTTGC GC-3' and reverse, 5'-TCCACTTCAAATGCTGCCAC-3'; $\beta$-actin forward, 5'-CCCTGGAGAAGAGCTACGAG-3' and reverse, 5'-CGTACAGGTCTTTGCGGATG-3'.

Statistical analysis. SPSS 22.0 software (IBM Corp., Armonk, NY, USA) was used for data analysis. All data are expressed as mean \pm standard deviation. Results were analyzed by two-tailed and unpaired Student's t-tests. One-way analysis of variance was used for comparison of multiple (>2) groups and Tukey's post hoc test for pairwise comparisons was used in this study. $\mathrm{P}<0.05$ was considered to indicate a statistically significant difference.

\section{Results}

Hypermethylation of the WIF-1 promoter is enhanced in lung cancer cell lines. To investigate whether TP has the ability to reverse the hypermethylation of the WIF-1 promoter, the methylation status of the WIF-1 promoter in non-small cell lung cancer A549, H460 and NCI-H446 cell lines was determined. The results revealed that the WIF-1 promoter was hypermethylated in A549, H460 and NCI-H446 cells, and that there was suppressed methylation in $\mathrm{HBE}$ cells compared with lung cancer cell lines (Fig. 1). Due to limitations in funding, only A549 and H460 cells were selected for subsequent analysis.

TP has a demethylation effect on the WIF-1 promoter in A549 and $H 460$ cells. In order to investigate whether treatment with TP has a demethylation effect on the WIF-1 promoter in A549 and H460 cells, an in vitro intervention experiment was performed. The results revealed that treatment with TP had a demethylation effect on A549 cells (Fig. 2A) and H460 cells (Fig. 2B) in a dose dependent manner $24 \mathrm{~h}$ post-treatment compared with the control. 
TP suppresses the proliferation of A549 cells. Previous studies have revealed that TP has potent tumor cytotoxicity (1-3). Therefore, the viability of A549 cells following treatment with TP was investigated. The results presented in Fig. 3A demonstrated that treatment with TP significantly suppressed the viability of A549 cells in a dose- and time-dependent manner, and that the relative cell viability reached $31.07 \% 24 \mathrm{~h}$ post-treatment with $3 \mu \mathrm{M}$ TP compared with the control.

TP significantly inhibits the invasion and migration of A549 cells. Compared with the control, the invasion and migration of A549 cells were markedly suppressed $24 \mathrm{~h}$ post-treatment with $0.03,0.3$ and $3 \mu \mathrm{M}$ TP (Fig. 3B and C). As revealed in Fig. 3B, the migration of A549 cells was significantly attenuated following treatment with TP in a dosage-dependent manner. Similarly, the invasion of A549 cells was significantly suppressed following treatment with TP $(0.3$ and $0.03 \mu \mathrm{M})$ compared with the control (Fig. 3C).

Demethylation of the WIF-1 promoter following treatment with TP increases the expression of WIF-1. To investigate the effects of TP on the expression levels of WIF-1in A549 cells, the mRNA and protein levels of WIF-1 were investigated. At $24 \mathrm{~h}$ post-treatment, the expression of WIF-1 protein in A549 cells was enhanced in a dose-dependent manner (Fig. 4A). The expression level of WIF-1 in cells treated with $3 \mu \mathrm{M}$ TP was $\sim 20$-fold that of the control. Furthermore, the WIF-1 mRNA expression level in A549 cells was significantly increased following TP treatment in a dose-dependent manner (Fig. 4B).

TP affects the expression of genes associated with apoptosis and proliferation. The results of the present study revealed that TP is associated with the expression of WIF-1 and the viability of A549 cells. Therefore, the present study aimed to investigate whether increased levels of WIF-1 expression, enhanced by treatment with TP, could inhibit the Wnt signaling pathway. Furthermore, the present study aimed to investigate whether treatment with TP affects the expression levels of matrix metalloproteinase-9 (MMP-9) and p53, as well as the activation of NF- $\kappa \mathrm{B}$ P65, which are associated with cell migration, apoptosis and survival. A notable increase regarding p53 expression was observed following treatment with TP $(3 \mu \mathrm{M})$ compared with control (Fig. 4C and D). By contrast, the expression level of MMP-9 was significantly decreased in cells treated with TP (Fig. 4C and D). The expression levels of $\beta$-catenin and Axin2, two key molecules of the Wnt pathway, were significantly decreased following treatment with TP compared with the control (Fig. 4C and D). Notably, the level of phosphorylated-P65 was also significantly decreased following treatment with TP (Fig. 4C and D). These results suggest that the Wnt and NF- $\mathrm{KB}$ signaling pathways were strongly suppressed following treatment with TP.

To further investigate the role of WIF-1 in the regulatory effect of TP on Wnt and NF- $\kappa \mathrm{B}$ pathways, WIF-1 expression was silenced by siRNA. As demonstrated in Fig. 5A and B, TP-induced elevations in levels of WIF-1 protein and mRNA were clearly downregulated compared with the control and siRNA negative control. The expression of p53 was significantly decreased in cells treated with $\mathrm{TP}+$ siRNA compared with cells treated with TP alone or
A
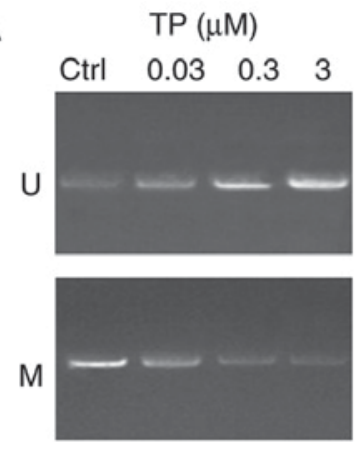

A549
B

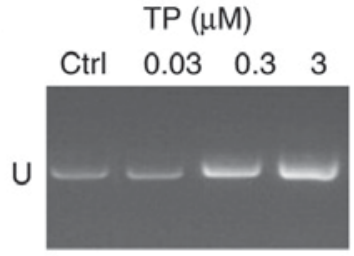

$\mathrm{M}$

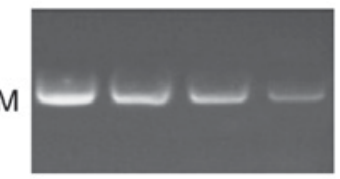

$\mathrm{H} 460$

Figure 2. Treatment with TP exhibits a marked demethlation effect on the WIF-1 promoter. Methylation-specific polymerase chain reaction assays demonstrated that the demethylation of the WIF-1 promoter was enhanced in a dose-dependent manner in (A) A549 and (B) H460 cells. U, unmethylated; M, methylated; WIF 1, Wnt inhibitory factor-1; TP, triptolide; Ctrl, control.

TP+NC (Fig. 5C). However, the level of p53 in cells treated with TP+siRNA was enhanced compared with the control. By contrast, MMP-9 expression in TP+siRNA cells was markedly enhanced compared with cells treated with TP alone or TP+NC, and lower than that exhibited by the control (Fig. 5C). In cells treated with TP+siRNA, the expression levels of Axin 2 and $\beta$-catenin were recovered to a similar level exhibited by the control, and significantly elevated compared with cells treated with either TP alone or TP+NC (Fig. 5D). There were no significant differences in levels of p-P65 exhibited among cells treated with TP+siRNA, TP alone or $\mathrm{TP}+\mathrm{NC}$ (Fig. 5D). These results suggest that $\mathrm{TP}$ not only suppresses the Wnt pathway by increasing WIF-1 expression, but also inhibits the NF- $\kappa \mathrm{B}$ pathway (which is not regulated by WIF-1).

\section{Discussion}

TP, a traditional Chinese medicine isolated from Tripterygium wilfordii, has been used to treat inflammation and autoimmune diseases (27). Numerous studies have demonstrated that TP exhibits antitumor effects on various cancer cell lines, including bladder, liver, cervical and breast cancer cell lines $(28,29)$. To investigate the effect of $\mathrm{TP}$ on the viability, invasion and migration of lung cancer cells, human lung cancer cell lines A549 and H460 were treated with TP. The results revealed that treatment with TP markedly suppressed the viability, invasion and migration of lung cancer cells. Furthermore, the results demonstrated that treatment with TP increased the expression levels of WIF-1 via demethylation of the WIF-1 promoter. Further investigation revealed that TP also increased the expression of p53, and decreased the levels of MMP-9 and p-P65, which are associated with cell apoptosis, proliferation, survival, invasion and migration (1-4).

The Wnt signaling pathway has an important function in the development of the embryo and is associated with the regulation of cell proliferation, differentiation and migration $(30,31)$. Hypermethylation of the WIF-1 promoter is associated with excessive activation of the Wnt signaling pathway in human lung cancer (24,32-34). Thus, restoring 

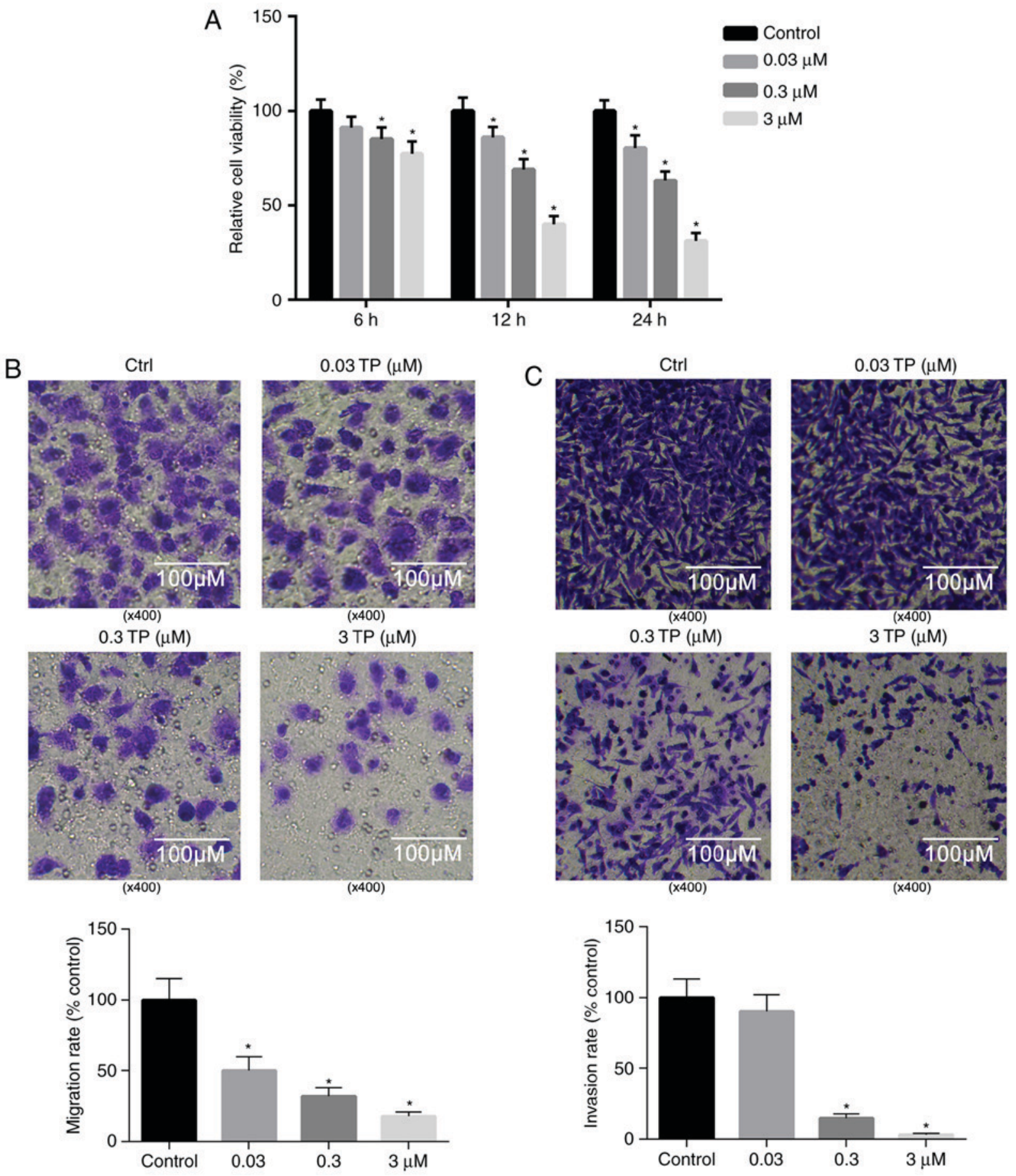

Figure 3. Treatment with TP affects cell viability, migration and invasion in A549 cells. (A) Cell Counting kit-8 assays demonstrated that TP suppressed the cell viability in a dosage- and time-dependent manner. (B) Transwell cell migration assay revealed that cell migration was significantly inhibited $24 \mathrm{~h}$ post-treatment of cells with TP $(0.03,0.3$ and $3 \mu \mathrm{M})$. (C) Transwell cell invasion assay demonstrated that cell invasion of A549 cells was significantly suppressed following treatment with TP, particularly when TP concentration was $3 \mu \mathrm{M}$. TP, triptolide; Ctrl, control. ${ }^{*} \mathrm{P}<0.05$ vs. control.

normal WIF-1 expression may downregulate the Wnt signaling pathway and inhibit the progression of lung cancer. In human tumors, abnormal methylation of $\mathrm{CpG}$ islands in promoter regions results in a suppression of the transcriptional activity of tumor suppressor genes (35-37). Previous studies have demonstrated that numerous tumor suppressor genes associated with lung cancer are downregulated via methylation of the promoter region $(23,35,38)$. Previous studies had also revealed that WIF-1 is silenced by hypermethylation of the associated promoter in lung cancer cell lines and lung cancer surgical specimens $(22,38)$. In addition, administration of the classic demethylation drug 5-aza-2'-deoxycytidine (DAC) demethylates the WIF-1 promoter to restore WIF-1 expression and thus restores downregulation of the activity of the Wnt signaling pathway $(39,40)$. Despite DAC exhibiting a well-established demethylation effect, its therapeutic use is limited by its toxic effects on cells $(41,42)$. $\mathrm{TP}$ is a natural compound that exhibits low cytotoxicity and a potential demethylation function, and thus may represent a novel therapeutic agent for the treatment of patients with 
A
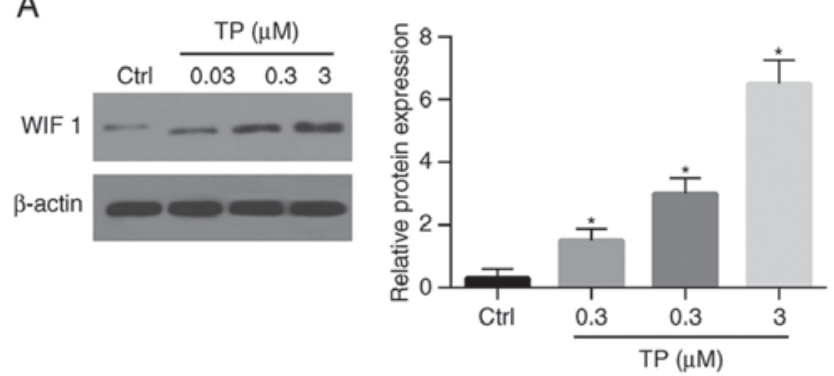

C
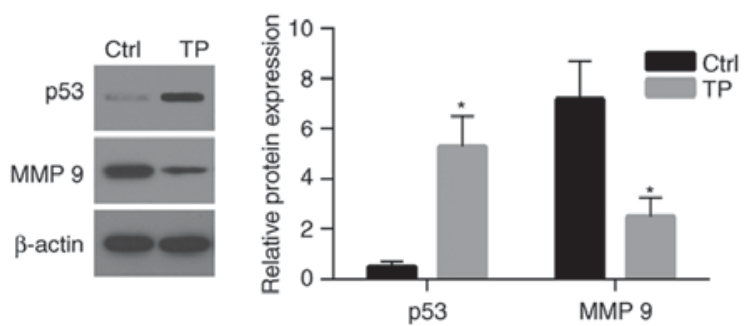

B
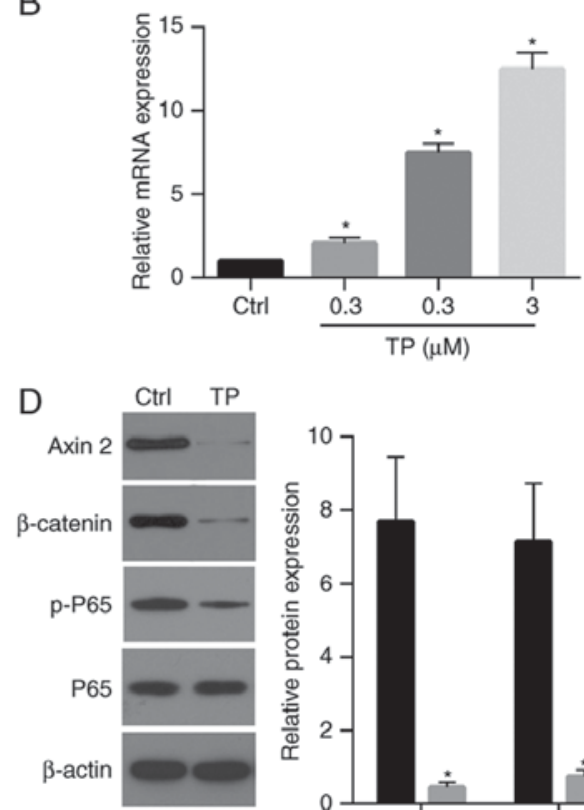

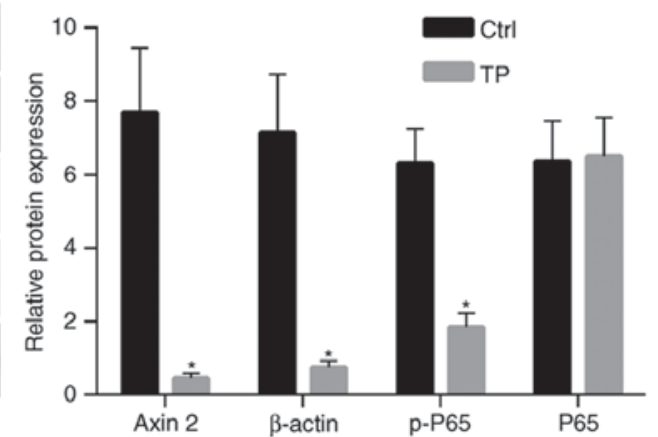

Figure 4. TP affects the expression of numerous genes associated with apoptosis, cell proliferation, migration and invasion. (A) Protein and (B) mRNA expression levels of WIF-1 were upregulated following treatment with TP in a dosage-dependent manner. Western blot assays demonstrated that the expression level of (C) p53 was significantly increased in cells treated with TP $(3 \mu \mathrm{M})$ compared with the control, and the level of MMP 9 was significantly decreased compared with the control. (D) The levels of Axin 2, $\beta$-catenin and p-P65 in cells treated with TP $(3 \mu \mathrm{M})$ were significantly decreased compared with the control. TP, triptolide; Ctrl, control; WIF 1, Wnt inhibitory factor-1; MMP-9, matrix metalloproteinase-9; p-, phospho-; P65, NK-кB P65. "P<0.05 vs. control.

lung cancer. The results of the present study revealed that treatment with TP significantly suppressed the viability, invasion and migration of A549 and H460 cells. In addition, the results demonstrated that TP markedly suppressed the degree of methylation of the WIF-1 promoter, thus inducing upregulation of WIF-1 expression. It was hypothesized that TP suppresses cell proliferation, invasion, migration and apoptosis by inhibiting the Wnt signaling pathway via upregulation of WIF-1 expression. Downregulated expression of Axin 2 and $\beta$-catenin suggested that treatment with TP suppresses the Wnt signaling pathway. Furthermore, an increase in 153 expression and a reduction in MMP-9 expression were observed, the results of which were consistent with the inhibition effect of TP on cell proliferation, migration and apoptosis.

TP had been demonstrated to exhibit significant growth inhibitory effects on various solid tumors such as breast cancer, gastrointestinal cancer, prostate cancer and nervous system tumors (43-45). TP has entered Phase I clinical trials, for the treatment of leukemia $(46,47)$. It has been revealed that TP exhibits an antitumor effect predominantly via inhibition of numerous transcriptional regulators such as $\mathrm{NF}-\kappa \mathrm{B}$ and AP-1, in which the NF- $\mathrm{KB}$ pathway is one of the most important antitumor targets $(5,29)$. P65 is an important heterodimer of NF- $\kappa B$. Inhibitor of $\kappa \mathrm{B}(\mathrm{I}-\mathrm{\kappa B})$ and NF- $\mathrm{kB}$ exist in the form of inactive complexes in the cytoplasm. Following activation, the NF- $\mathrm{KB} / \mathrm{I}-\kappa \mathrm{B}$ complex dissociates and releases free NF- $\kappa \mathrm{B}$ into the nucleus to regulate the transcription of the target genes (48-50). Notably, the level of p-P65 was downregulated in cells post-treatment with TP, which is consistent with the observations of previous studies (51-53). Recently, similar studies determined that TP not only inhibits
NF-kB nuclear translocation in human lung adenocarcinoma paclitaxel-resistant cell line A549/Taxol, but also inhibits the function of RNA polymerase II $(54,55)$.

The results of the present study revealed that knockdown of WIF-1 with siRNA resulted in a significant reduction of WIF-1 expression. As hypothesized, compared with cells treated with TP, the expression levels of Axin 2 and $\beta$-catenin in cells with additional siRNA treatment were increased and recovered to that exhibited by the control (cells without treatment), thus suggesting that the Wnt signaling pathway was activated. Silencing WIF-1 blocked TP-induced inhibition of the Wnt signaling pathway, thus suggesting that TP-induced inhibition of Wnt signaling pathway is WIF-1 dependent. Despite activation of Wnt signaling simulated by knockdown of WIF-1 not completely recovering the expression levels of p53, MMP-9 and p-P65 in cells treated with TP compared with the control, the results do suggest that treatment with TP affects p53 and NF- $\kappa \mathrm{B}$ signaling pathways. Consistent with the results of the present study, Jiang et al (6) demonstrated that TP has anti-inflammatory and antitumor functions via suppression of cell proliferation, induction of apoptosis and downregulation of NF- $\mathrm{kB}$ and AP-1 transcriptional activity. In addition, previous studies have demonstrated that $\mathrm{p} 53$ activity is important for the anti-inflammatory, antitumor and pro-apoptotic effects of TP treatment on human gastric cancer cells $(6,56)$.

The present study was limited due to funding; only A549 and H460 cells were investigated. Therefore, the findings of the present stud require further investigation with additional cell lines and analysis in vivo. In conclusion, the results of the present study suggested that promoter hypermethylation of WIF-1 is responsible for the abnormal 

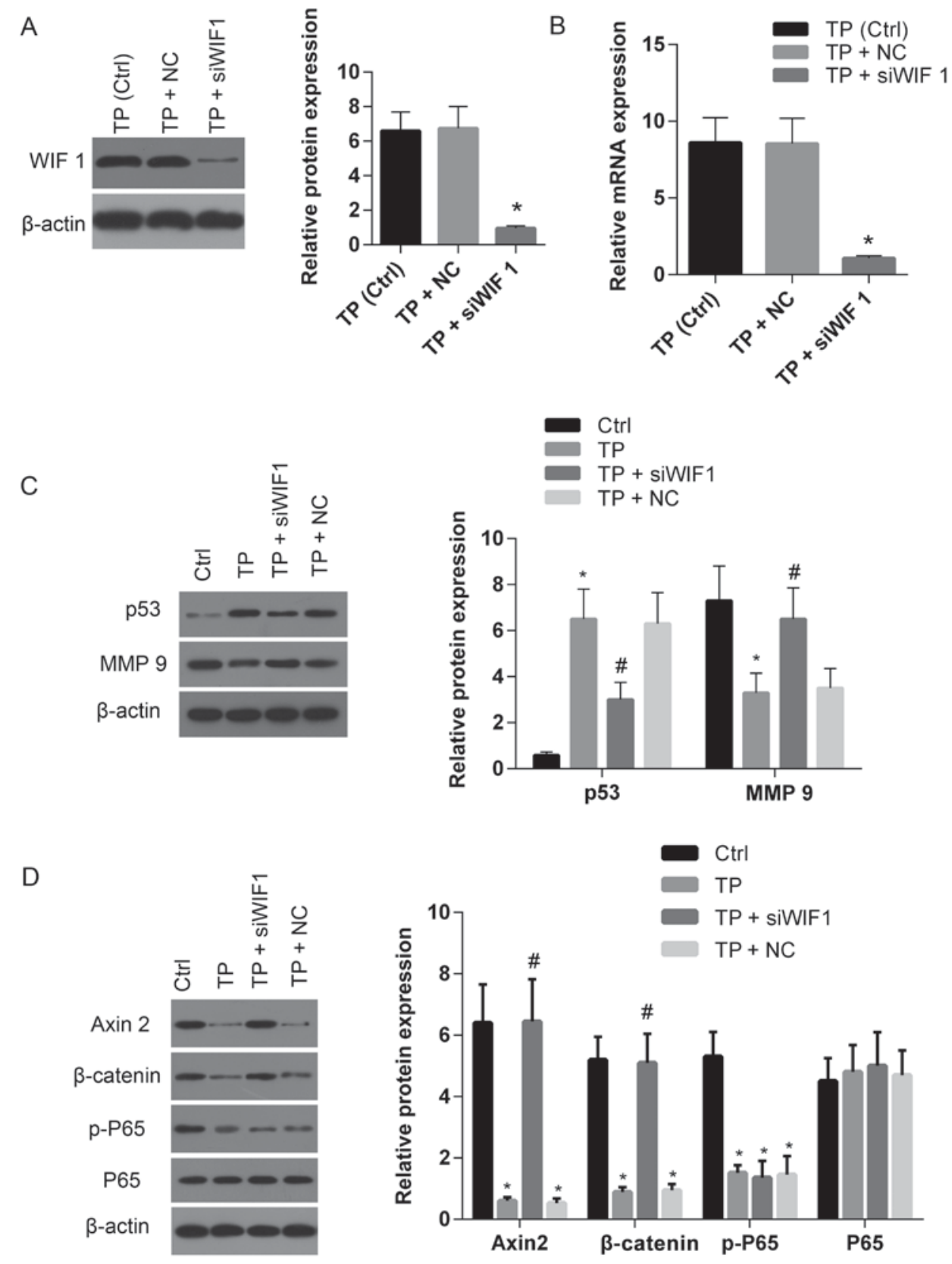

Figure 5. Silencing WIF-1 expression partially attenuates the effect of TP on the expression of several genes associated with apoptosis and cell proliferation, migration and invasion. The (A) protein and (B) mRNA expression levels of WIF-1 in cells treated with TP (3 $\mu \mathrm{M})$ were downregulated following treatment with siWIF 1 compared with cells treated with TP alone or the negative control. (C) The protein levels of p53 and MMP-9 in cells treated with TP+siWIF 1 were markedly enhanced and suppressed compared with the control, respectively; whereas the protein levels of p53 and MMP-9 in cells treated with TP+siWIF 1 were markedly suppressed and enhanced compared with cells treated with TP alone. (D) The protein levels of Axin 2 and $\beta$-catenin in cells treated with TP+siWIF 1 were restored to the associated levels exhibited by the control, whereas there was no significant change regarding the level of p-P65 in cells treated with TP+siWIF 1 compared with cells treated with TP alone or negative control (TP+NC). TP, triptolide; Ctrl, control; NC, negative control;

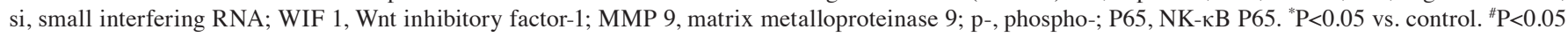
TP+siWIF 1 vs. TP+NC or TP.

activation of Wnt signaling in lung cancer cells. TP exhibits significant inhibition on Wnt signaling via demethylation of the WIF-1 promoter. Silencing WIF-1 with siRNA reversed TP-induced inhibition of Wnt signaling, thus suggesting that TP-induced suppression of Wnt signaling is WIF-1 dependent. Furthermore, upregulation of p53, and downregulation of MMP-9 and p-P65, was observed in cells treated with TP. Notably, silencing WIF-1 did not restore the levels of p53, MMP-9 and p-P65 in cells treated with TP to those exhibited by the control, thus suggesting that $\mathrm{p} 53$ and $\mathrm{NF}-\kappa \mathrm{B}$ signaling pathways also have important roles in the antitumor effect of TP on lung cancer cells.

\section{Acknowledgements}

Not applicable.

\section{Funding}

No funding was received. 


\section{Availability of data and materials}

All data generated and/or analyzed during this study are included in this published article.

\section{Authors' contributions}

$\mathrm{XM}$ and JT wrote the manuscript. XM conducted cell culture and treatments, cell proliferation and Transwell cell migration assays, and reverse transcription-quantitative polymerase chain reaction and western blot analyses. YoW and ZZ performed cell culture and treatment, cell proliferation assay, cell transfection and Transwell cell migration assay. YY and YeW performed methylation-specific polymerase chain reaction and reverse transcription-quantitative polymerase chain reaction. XM and JT made substantial contributions to the design of the study. $\mathrm{XM}$ and YoW analysed data. XM and JT critically revised the manuscript for important intellectual content. All authors read and approved the final the manuscript.

\section{Ethics approval and consent to participate}

Not applicable.

\section{Patient consent for publication}

Not applicable.

\section{Competing interests}

The authors declare that they have no competing interests.

\section{References}

1. Zhao F, Chen Y, Li R, Liu Y, Wen L and Zhang C: Triptolide alters histone $\mathrm{H} 3 \mathrm{~K} 9$ and $\mathrm{H} 3 \mathrm{~K} 27$ methylation state and induces G0/G1 arrest and caspase-dependent apoptosis in multiple myeloma in vitro. Toxicology 267: 70-79, 2010.

2. Borja-Cacho D, Yokoyama Y,Chugh RK, Mujumdar NR, Dudeja V, Clawson KA, Dawra RK, Saluja AK and Vickers SM: TRAIL and triptolide: An effective combination that induces apoptosis in pancreatic cancer cells. J Gastrointest Surg 14: 252-260, 2010.

3. Wang W, Li X, Sun W, Zhang L, Zhang M, Hong B and Lv G: Triptolide triggers the apoptosis of pancreatic cancer cells via the downregulation of Decoy receptor 3 expression. J Cancer Res Clin Oncol 138: 1597-1605, 2012.

4. Pan J: RNA polymerase-an important molecular target of triptolide in cancer cells. Cancer Lett 292: 149-152, 2010.

5. Wu Y, Cui J, Bao X, Chan S, Young DO, Liu D and Shen P: Triptolide attenuates oxidative stress, NF-kappaB activation and multiple cytokine gene expression in murine peritoneal macrophage. Int J Mol Med 17: 141-150, 2006.

6. Jiang XH, Wong BC, Lin MC, Zhu GH, Kung HF, Jiang SH, Yang D and Lam SK: Functional p53 is required for triptolide-induced apoptosis and AP-1 and nuclear factor-kappaB activation in gastric cancer cells. Oncogene 20: 8009-8018, 2001

7. Mackenzie TN, Mujumdar N, Banerjee S, Sangwan V, Sarver A Vickers S, Subramanian S and Saluja AK: Triptolide induces the expression of miR-142-3p: A negative regulator of heat shock protein 70 and pancreatic cancer cell proliferation. Mol Cancer Ther 12: 1266-1275, 2013.

8. Gil L and Adonis M: Genomics and proteomics offers new hopes towards a personalized approach to lung cancer prevention and treatment. Elec J Biotechnol 6: 401-409, 2003.

9. Lemos C, Kathmann I, Giovannetti E, Calhau C, Jansen G and Peters GJ: Impact of cellular folate status and epidermal growth factor receptor expression on $\mathrm{BCRP} / \mathrm{ABCG} 2$-mediated resistance to gefitinib and erlotinib. Br J Cancer 100: 1120-1127, 2009.
10. Sun JM, Won YW, Kim ST, Kim JH, Choi YL, Lee J, Park YH, Ahn JS, Park K and Ahn MJ: The different efficacy of gefitinib or erlotinib according to epidermal growth factor receptor exon 19 and exon 21 mutations in Korean non-small cell lung cancer patients. J Cancer Res Clin Oncol 137: 687-694, 2011.

11. Rho JK, Choi YJ, Jeon BS, Choi SJ, Cheon GJ, Woo SK, Kim HR, Kim CH, Choi CM and Lee JC: Combined treatment with silibinin and epidermal growth factor receptor tyrosine kinase inhibitors overcomes drug resistance caused by T790M mutation. Mol Cancer Ther 9: 3233-3243, 2010.

12. Reya $\mathrm{T}$ and Clevers $\mathrm{H}$ : Wnt signalling in stem cells and cancer Nature 434: 843-850, 2005.

13. Yamulla RJ, Kane EG, Moody AE, Politi KA, Lock NE, Foley AV and Roberts DM: Testing models of the APC tumor suppressor/ $\beta$-catenin interaction reshapes our view of the destruction complex in Wnt signaling. Genetics 197: 1285-1302, 2014.

14. Logan CY and Nusse R: The Wnt signaling pathway in development and disease. Annu Rev Cell Dev Biol 20: 781-810, 2004.

15. Sun J and Jin T: Both Wnt and mTOR signaling pathways are involved in insulin-stimulated proto-oncogene expression in intestinal cells. Cell Signal 20: 219-229, 2008.

16. Huang C, Ma R, Xu Y, Li N, Li Z, Yue J, Li H, Guo Y and Qi D: Wnt2 promotes non-small cell lung cancer progression by activating WNT/ $\beta$-catenin pathway. Am J Cancer Res 5: 1032-1046, 2015.

17. Benhaj K, Akcali KC and Ozturk M: Redundant expression of canonical Wnt ligands in human breast cancer cell lines. Oncol Rep 15: 701-707, 2006.

18. Akiri G, Cherian MM, Vijayakumar S, Liu G, Bafico A and Aaronson SA: Wnt pathway aberrations including autocrine Wnt activation occur at high frequency in human non-small-cell lung carcinoma. Oncogene 28: 2163-2172, 2009.

19. Uematsu K, He B, You L, Xu Z, McCormick F and Jablons DM: Activation of the Wnt pathway in non small cell lung cancer: Evidence of dishevelled overexpression. Oncogene 22: 7218-7221, 2003.

20. Kim J, You L, Xu Z, Kuchenbecker K, Raz D, He B and Jablons D: Wnt inhibitory factor inhibits lung cancer cell growth. J Thorac Cardiovasc Surg 133: 733-737, 2007.

21. Ai L, Tao Q, Zhong S, Fields CR, Kim WJ, Lee MW, Cui Y, Brown KD and Robertson KD: Inactivation of Wnt inhibitory factor-1 (WIF1) expression by epigenetic silencing is a common event in breast cancer. Carcinogenesis 27: 1341-1348, 2006.

22. Gao Z, Xu Z, Hung MS, Lin YC, Wang T, Gong M, Zhi X, Jablons DM and You L: Procaine and procainamide inhibit the Wnt canonical pathway by promoter demethylation of WIF-1 in lung cancer cells. Oncol Rep 22: 1479-1484, 2009.

23. Lee SM, Park JY and Kim DS: Wif1 hypermethylation as unfavorable prognosis of non-small cell lung cancers with EGFR mutation. Mol Cells 36: 69-73, 2013.

24. Tan M, Wu J and Cai Y: Suppression of Wnt signaling by the miR-29 family is mediated by demethylation of WIF-1 in non-small-cell lung cancer. Biochem Biophys Res Commun 438: 673-679, 2013.

25. Liu YL, Yang HP, Gong L, Tang CL and Wang HJ: Hypomethylation effects of curcumin, demethoxycurcumin and bisdemethoxycurcumin on WIF-1 promoter in non-small cell lung cancer cell lines. Mol Med Rep 4: 675-679, 2011.

26. Livak KJ and Schmittgen TD: Analysis of relative gene expression data using real-time quantitative PCR and the 2(-Delta Delta C(T)) method. Methods 25: 402-408, 2001.

27. Morita T: Celastrol: A new therapeutic potential of traditional chinese medicine. Am J Hypertens 23: 821, 2010.

28. Ho JN, Byun SS, Lee S, Oh JJ, Hong SK, Lee SE and Yeon JS: Synergistic antitumor effect of triptolide and cisplatin in cisplatin resistant human bladder cancer cells. J Urol 193: 1016-1022, 2015.

29. Liu J, Jiang Z, Xiao J, Zhang Y, Lin S, Duan W, Yao J, Liu C, Huang X, Wang T, et al: Effects of triptolide from Tripterygium wilfordii on ERalpha and p53 expression in two human breast cancer cell lines. Phytomedicine 16: 1006-1013, 2009.

30. Yao H, Ashihara E and Maekawa T: Targeting the Wnt/ $\beta$-catenin signaling pathway in human cancers. Expert Opin Ther Targets 15: 873-887, 2011.

31. Varela-Nallar L, Grabowski CP, Alfaro IE, Alvarez AR and Inestrosa NC: Role of the Wnt receptor Frizzled-1 in presynaptic differentiation and function. Neural Dev 4: 41, 2009.

32. Mazières J, You L, He B, Xu Z, Lee AY and Jablons DM: Wnt Inhibitory Factor 1 (WIF-1) silencing in human non-small cell lung cancer is controlled by promoter hypermethylation. Cancer Res 65: 430-430, 2005. 
33. Liu YL, Yang HP, Zhou XD, Gong L, Tang CL and Wang HJ: The hypomethylation agent bisdemethoxycurcumin acts on the WIF-1 promoter, inhibits the canonical Wnt pathway and induces apoptosis in human non-small-cell lung cancer. Curr Cancer Drug Targets 11: 1098-1110, 2011.

34. Xie J, Zhang Y, Hu X, Lv R, Xiao D, Jiang L and Bao Q: Norcantharidin inhibits Wnt signal pathway via promoter demethylation of WIF-1 in human non-small cell lung cancer. Med Oncol 32: 145, 2015

35. Esteller M: CpG island hypermethylation and tumor suppressor genes: A booming present, a brighter future. Oncogene 21: 5427-5440, 2002.

36. Sandoval J, Heyn H, Moran S, Serra-Musach J, Pujana MA, Bibikova M and Esteller M: Validation of a DNA methylation microarray for $450,000 \mathrm{CpG}$ sites in the human genome. Epigenetics 6: 692-702, 2011.

37. Li Y, Pan P, Qiao P and Liu R: Downregulation of N-myc downstream regulated gene 1 caused by the methylation of $\mathrm{CpG}$ islands of NDRG1 promoter promotes proliferation and invasion of prostate cancer cells. Int J Oncol 47: 1001-1008, 2015.

38. He B, You L, Xu Z, Lee A, Reguart N, Rossel R and Jablons D: O-003 Writ inhibitory factor-1 (WIF-1) is silenced by promoter hypermethylation in human non-small cell lung cancer. Lung Cancer 49: S5, 2005.

39. Delmas AL, Riggs BM, Pardo CE, Dyer LM, Darst RP Izumchenko EG, Monroe M, Hakam A, Kladde MP, Siegel EM and Brown KD: WIF1 is a frequent target for epigenetic silencing in squamous cell carcinoma of the cervix. Carcinogenesis 32: $1625-1633,2011$.

40. Chan SL, Cui Y, van Hasselt A, Li H, Srivastava G, Jin H, Ng KM, Wang Y, Lee KY, Tsao GS, et al: The tumor suppressor Wnt inhibitory factor 1 is frequently methylated in nasopharyngeal and esophageal carcinomas. Lab Invest 87: 644-650, 2007.

41. Bai W, Chen Y and Gao A: Cross talk between poly (ADP-ribose) polymerase 1 methylation and oxidative stress involved in the toxic effect of anatase titanium dioxide nanoparticles. Int J Nanomedicine 10: 5561-5569, 2015.

42. Hodge DR, Peng B, Cherry JC, Hurt EM, Fox SD, Kelley JA, Munroe DJ and Farrar WL: Interleukin 6 supports the maintenance of p53 tumor suppressor gene promoter methylation. Cancer Res 65: 4673-4682, 2005.

43. Dai D, Musser JH and Lennox ES: Triptolide derivatives for modulation of apoptosis and immunosuppression. US Patent 7,847,109. Filed May 29, 2003; issued December 7, 2010.

44. Liang $\mathrm{M}$ and $\mathrm{Fu} \mathrm{J}$ : Triptolide inhibits interferon-gamma-induced programmed death-1-ligand 1 surface expression in breast cancer cells. Cancer Lett 270: 337-341, 2008.

45. Huang W, He T, Chai C, Yang Y, Zheng Y, Zhou P, Qiao X, Zhang B, Liu Z, Wang J, et al: Triptolide inhibits the proliferation of prostate cancer cells and down-regulates SUMO-specific protease 1 expression. PLoS One 7: e37693, 2012.
46. Li L, Kanwar J, Schmitt S, Cui QC, Zhang C, Zhao C and Dou QP: Inhibition of tumor cellular proteasome activity by triptolide extracted from the Chinese medicinal plant 'thunder god vine'. Anticancer Res 31: 1-10, 2011.

47. Shi X, Jin Y, Cheng C, Zhang H, Zou W, Zheng Q, Lu Z, Chen Q Lai Y and Pan J: Triptolide inhibits Bcr-Abl transcription and induces apoptosis in STI571-resistant chronic myelogenous leukemia cells harboring T315I mutation. Clin Cancer Res 15: 1686-1697, 2009

48. Campbell KJ, Rocha S and Perkins ND: Active repression of antiapoptotic gene expression by RelA (p65) NF-kappa B. Mol Cell 13: 853-865, 2004.

49. Lu W, Zhang G, Zhang R, Flores LG II, Huang Q, Gelovani JG and Li C: Tumor site-specific silencing of NF-kappaB p65 by targeted hollow gold nanosphere-mediated photothermal transfection. Cancer Res 70: 3177-3188, 2010.

50. Moles A, Butterworth JA, Sanchez A, Hunter JE, Leslie J, Sellier H, Tiniakos D, Cockell SJ, Mann DA, Oakley F and Perkins ND: A RelA (p65) Thr505 phospho-site mutation reveals an important mechanism regulating NF- $\mathrm{kB}$-dependent liver regeneration and cancer. Oncogene 35: 4623-4632, 2016.

51. Zhou Y, Hong Y and Huang H: Triptolide attenuates inflammatory response in membranous glomerulo-nephritis rat via downregulation of NF- $\kappa \mathrm{B}$ signaling pathway. Kidney Blood Press Res 41: 901-910, 2016.

52. Jang BC, Lim KJ, Choi IH, Suh MH, Park JG, Mun KC, Bae JH, Shin DH and Suh SI: Triptolide suppresses interleukin-1beta-induced human beta-defensin-2 mRNA expression through inhibition of transcriptional activation of NF-kappaB in A549 cells. Int J Mol Med 19: 757-763, 2007.

53. Wang X, Zhang L, Duan W, Liu B, Gong P, Ding Y and Wu X: Anti-inflammatory effects of triptolide by inhibiting the NF- $\kappa B$ signalling pathway in LPS-induced acute lung injury in a murine model. Mol Med Rep 10: 447-452, 2014.

54. Wang Y, Lu JJ, He L and Yu Q: Triptolide (TPL) inhibits global transcription by inducing proteasome-dependent degradation of RNA polymerase II (Pol II). PLoS One 6: e23993, 2011.

55. Vispé S, Devries L, Créancier L, Besse J, Bréand S, Hobson DJ, Svejstrup JQ, Annereau JP, Cussac D, Dumontet C, et al: Triptolide is an inhibitor of RNA polymerase I and II-dependent transcription leading predominantly to down-regulation of short-lived mRNA. Mol Cancer Ther 8: 2780-2790, 2009.

56. Carter BZ, Mak DH, Schober WD, Dietrich MF, Pinilla C, Vassilev LT, Reed JC and Andreeff M: Triptolide sensitizes AML cells to TRAIL-induced apoptosis via decrease of XIAP and p53-mediated increase of DR5. Blood 111: 3742-3750, 2008. 